\title{
La relatoría crítica y la formación de pensamiento autónomo e inclusivo
}

| Julio César Arboleda

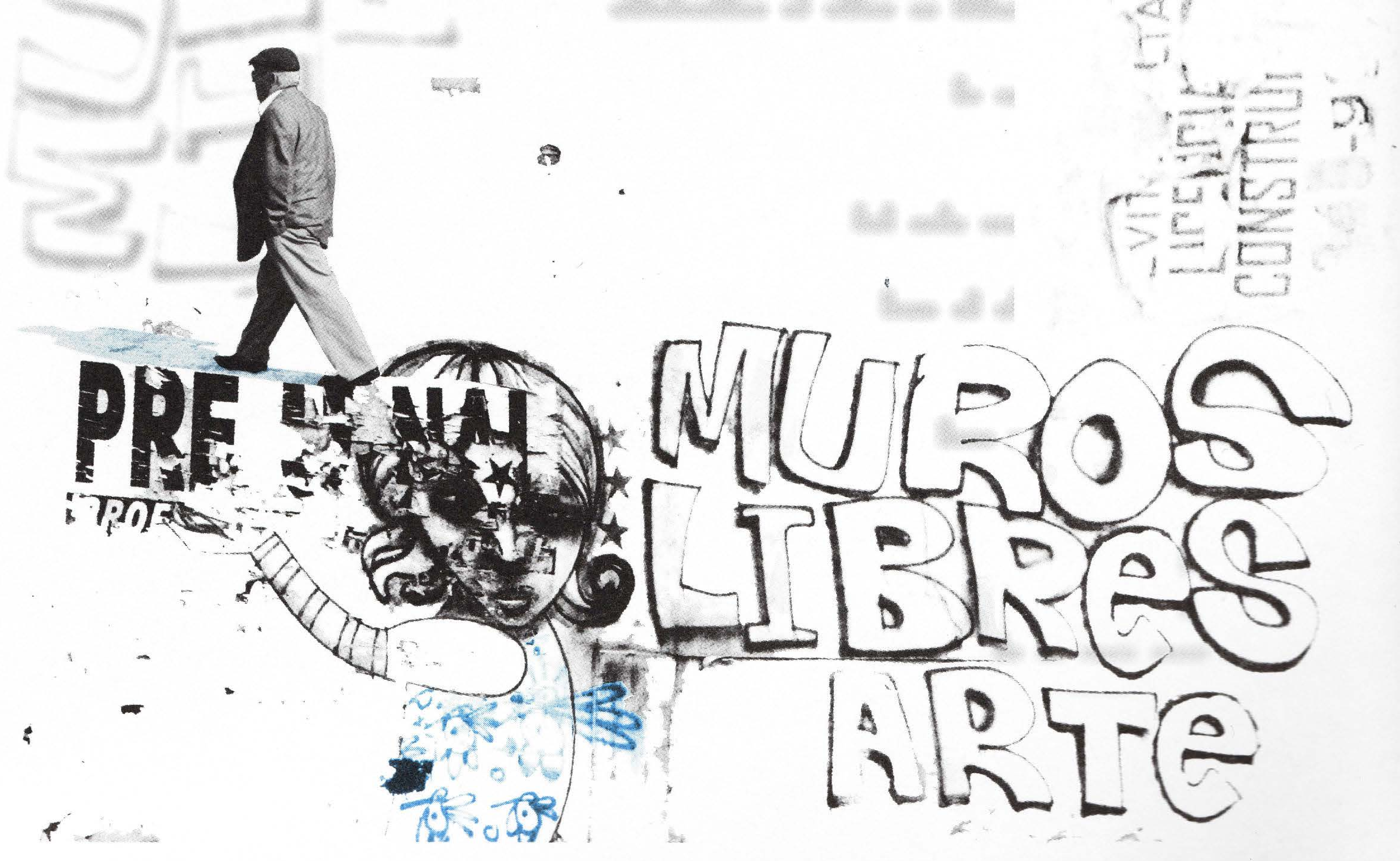


Julio César Arboleda es creador y asesor del enfoque Pedagogía por proyectos de vida y Desarrollo de comprensiones. Asesor Red Iberoamericana de Pedagogía y docencia investigativa. Director científico Fundación PENSER. Coordinador del Nodo Centroccidente de la Red de lectura y escritura para la educación superior, REDLEES. Investigador grupos Educación (UAO), Ciencias del lenguaje y Sinergias (USC). Autor de los textos: Metodología del aprendizaje por competencias, comprensiones y proyectos de vida (F.P., 2007), Estrategias para la comprensión significativa (ed. Magisterio, 2005), Mapas cognitivos(Lei, 2000), Pensamiento lateral y aprendizajes (ed. Magisterio, 2007), Modelos pedagógicos autónomos (FP-UAC, 2007).Correo electrónico: j.c.arboleda@ hotmail.com, reddepedagogia@yahoo.com

Resumen
Este artículỏ propone institucionalizar y utilizar transversalmente la relatoría crítica como
una herramienta para mejorar e impulsar procesos, tanto de apropiación de conocimientos
en todas las áreas y niveles de escolaridad, como de formación de sujetos educables críticos,
éticos y autónomos, que decidan por sí mismos y procedan en la vida con mayoría de edad.
Inicialmente se describen las características y estructura de este tipo de texto, aportando
una definición del mismo, así como estrategias para su elaboración y uso en el aula de clase;
luego, se sustenta la importancia de convertirlo en una herramienta cotidiana en la actividad
educativa dada su pertinencia en la formación integral, incluida la capacidad de pensamiento
crítico, autónomo y ético.

\section{Palabras claves: Pensamiento crítico, pensamiento autónomo, relatoría crítica, comprensión cognitiva, producción discursiva}

\section{Abstract}

The author proposes the use of critical narrative as a tool in order to improve appropriation of knowledge in all areas and levels of schooling; this shall also be of importance in order to prepare critical, ethical and autonomous individuals who could be able to decide by themselves. It also draws the attention on the characteristics of this type of texts, including several strategies to prepare such documents during the classes.

Key Words : Critical thought, autonomous thought, critical narrative, cognitive understanding, discourse production 


\section{¿Qué es una relatoría crítica?}

La relatoría crítica es un tipo de texto expositivoargumentativo, mediante el cual se describen, analizan, interpretan, evalúan y generan ideas, afirmaciones, conceptos o tópicos relevantes en un texto, situación u objeto de estudio, asumiendo una posición personal, respaldada por argumentos fiables. A continuación se examina cada aseveración de esta definición.

En primer lugar, es preciso reconocer el carácter plural de la relatoría ${ }^{1}$. A la relatoría descriptiva, por ejemplo, le compete relacionar los momentos de un evento, sea este una asamblea, encuentro, observación o cualquier otro del que haya necesidad de dejar constancia; la relatoría cognitiva describe - proceso inherente a todo tipo de relatoría, del cual no se puede negar su carácter cognitivo- comunicativo - y explica ideas relevantes en un evento u objeto de conocimiento, dando cuenta de los procesos y operaciones básicas para la construcción y argumentación de estas; la relatoría conceptual describe y sustenta, en particular, características, relaciones y aplicaciones relevantes en uno o varios conceptos; la relatoría de comprensión expone y explica los procesos de aplicación o vivenciación de un conocimiento, incluida la utilidad que estas generan a nivel personal o social. En esta línea se encuentran las relatorías polifónica, lateral y metacognitiva, entre otras que hemos definido ${ }^{2}$. Ahora sigue lo que subyace a la relatoría crítica como texto expositivo argumentativo.
En el trabajo académico esta relatoría representa una de las herramientas cognitivas y discursivas que informan acerca de la capacidad de un estudiante o profesor para apropiarse de un conocimiento. En un proceso de formación de estudiantes (o de profesores) es necesario buscar evidencias de cognición, de apropiación del conocimiento por parte del sujeto educable; este debe exponer declaraciones relevantes en un objeto de acercamiento, ofreciendo razones adecuadas y fiables frente a las mismas, entre otros procesos cognitivos. En esta vía, la relatoría crítica constituye una herramienta discursiva que organiza la manera como el sujeto cognitivo puede presentar su conocimiento en construcción frente a un tema o evento de estudio ${ }^{3}$, exigiendo el uso de diversas operaciones cognitivas. Por una parte, demanda capacidad de elaboración de ideas, es decir de convertir un dato o información relevante en conocimiento ${ }^{4}$; también, de clasificar en tópicos (temas o aspectos) estas y la información general relativa al texto u objeto de estudio ${ }^{5}$; así mismo, de establecer relaciones entre ideas- tópicos, incluida la síntesis y otros procesos del razonamiento.

1 Una categorización de este tipo de texto la realizó en Arboleda (2004- 2005).

2 Desde el año 2003 desarrollo en los grupos de investigación Educación (UAO) y Ciencias del lenguaje (USC) un proyecto en el que se caracterizan y aplican los tipos de relatoría relacionados.

3 Vease el siguiente punto: estructura de la relatoría crítica.

4 Sintetizando lo que he expresado en otros espacios sobre la diferencia entre información y conocimiento, puedo decir que quien memoriza repite información, pero quien logra interpretar esta, determinar o sintetizar de qué se habla, qué se dice y porqué se dice, entra al proceso de construcción de conocimiento, de representación del conocimiento. Una cosa es repetir información y otra representarse esta como conocimiento. Ver, Arboleda 1996, 2000, 2004, 2005, 2007.

5 Una idea puede hacer parte de uno o varios tópicos. En realidad, es arbitrario determinar qué proceso sigue a otro, qué operación antecede a otra, pues existen varios métodos y estrategias de procesamiento determinadas por las características del sujeto y el objeto de conocimiento. 
En este orden de exposición, el relator debe saber representar las ideas, sean estas literales o inferidas, elaboradas por él mismo como producto de su ejercicio de síntesis o parafraseo, a través de constructos lingüísticos tales como las oraciones, en particular las proposiciones, y desarrollarlas (argumentarlas, esclarecerlas) mediante párrafos, hilando estos, sin dejar de utilizar o elaborar expresiones que hagan explícita la conexión entre los mismos. De esta manera se prueba su capacidad de análisis, de abordar un corpus discursivo (tema de clase, lectura, vídeo, exposición) diferenciando sus partes (tópicos, ideas), examinando y explicando cada una de estas, $\mathrm{y}$ estableciendo relaciones êntre las mismas. Tal análisis debe ser crítico, es decir debe generar capacidad de reacción por parte de aquel ante las declaraciones incluidas en la información. En efecto, el sujeto crítico no deja de digerir o explicitar un enunciado: siempre manifiesta su reacción frente al mismo: su aprobación o desaprobación, sustentando su elección, ofreciendo y explicando sus mejores razones, presentando los mejores hechos, razonamientos o reflexiones propias o de otros que las respalden.

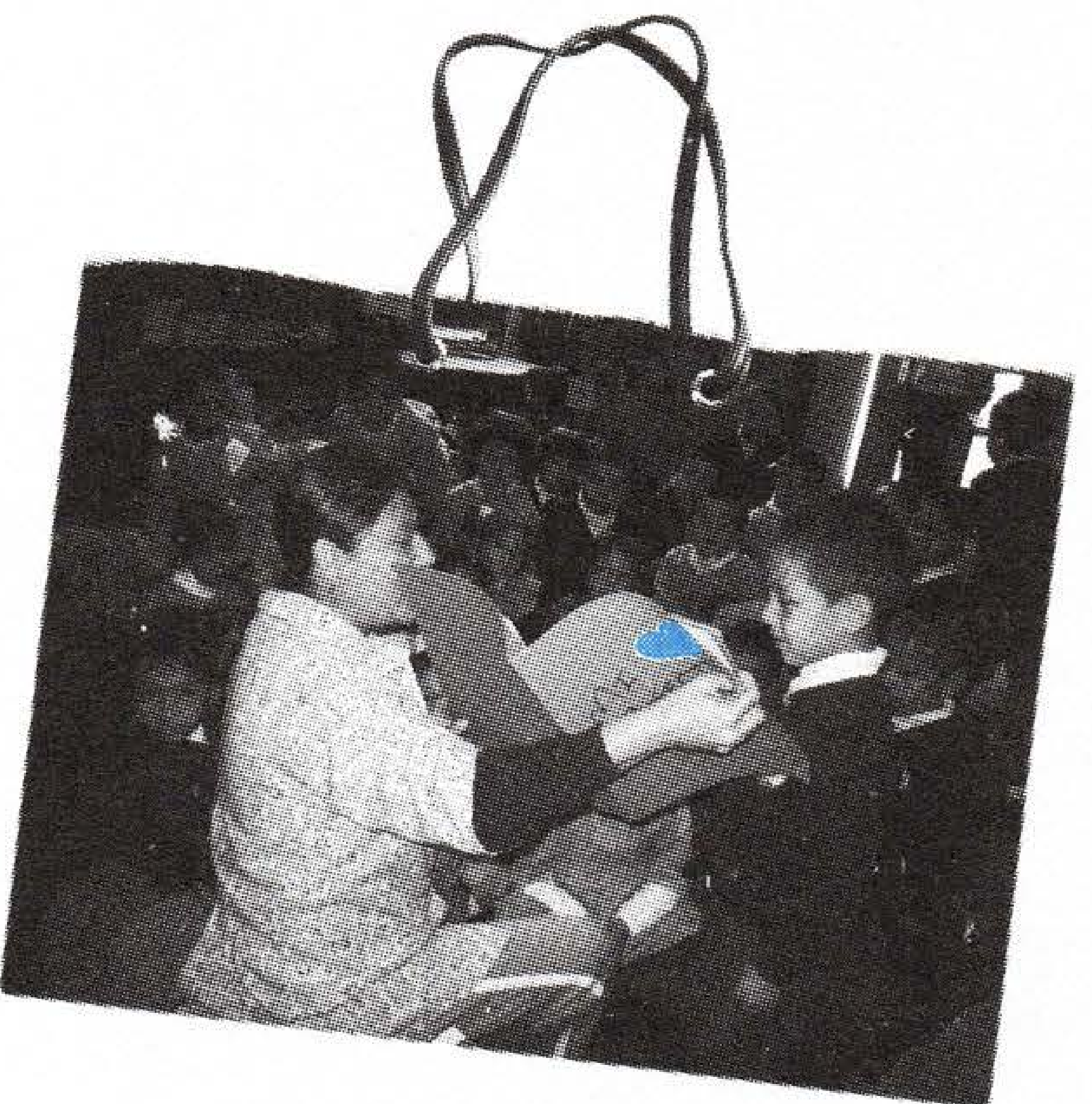

Por otra parte, la relatoría crítica hace evidente el proceso de evaluación. Este es recurrente en todo el acto cognitivo discursivo. Los actos cognitivos del relator tales como la identificación, elaboración y presentación de ideas o tópicos requieren inicialmente de un diagnóstico. Por ejemplo, para inferir o determinar una idea a partir de un evento o discurso este indaga de manera tácita o deliberada por el sujeto (de quién o de qué se habla) y por lo que se predica o dice de este; análogamente en el acto discursivo, para elaborar o proyectar estas en un texto oral, escrito u otro. Así mismo, para emitir un juicio de valor; este es fiable si, entre otros aspectos, lo precede el reconocimiento, por parte del sujeto crítico, de los hechos o reflexiones que lo respalden de modo que descarte las mayores posibilidades de contradicción en sí mismo y por la realidad ${ }^{6}$.

Finalmente, la relatoría constituye, en sí misma, no solo un dispositivo para fortalecer la competencia discursiva (conocimientos, capacidades, habilidades, destrezas y actitudes expresivas), sino también, adecuadamente orientada, la comprensión, es decir el potencial para reflexionar, generar y operar de manera edificadora con el conocimiento en el mundo de la vida ${ }^{7}$. Alguien puede ser hábil en el campo discursivo porque logra expresar sus conocimientos, pensamientos e interpretaciones de manera adecuada, pero si es capaz de hacerlo con pensamiento crítico, en el sentido que aquí se le confiere a este, tal como lo precisa la relatoría en referencia, no solo demuestra capacidad de capturar y expresar discursivamente un objeto de estudio, sino potencial de autodesarrollo, de generación de oportunidades y capacidades para ser mejor persona.

6 Un juicio de esta naturaleza correspondería a lo que Lipman denomina juicios inteligentes, aquellos que están basados en argumentos fuertes, en criterios de peso.

7 En otro espacio (Arboleda, 2008A) he sometido a escrutinio público mi crítica al sistema educativo basado en competencias, por cuanto, entre otras razones, los procesos básicos que este demanda (conocimiento, capacidades, habilidad y destreza para apropiarse y utilizar el conocimiento) constituyen ya una exigencia del enfoque de comprensión y proyectos de vida, con la diferencia de que la finalidad que este otorga al uso del conocimiento es el desarrollo humano y de la vida, mientras que la de aquel es la acumulación de la riqueza con base en la eficiencia y la rentabilidad que generan las personas competentes. 
Enseguida se relacionan los componentes de la relatoría crítica, ilustrando cómo en esta se ponen de presente las características y propiedades que se acaban de referir.

\section{Componentes}

La estructura de la relatoría es la siguiente: título, fuente, texto o situación de referencia, relator, introducción, análisis crítico y síntesis proactiva.

Título. Se sugiere que este incluya el concepto central que se aborda en la actividad escolar. Si se trata de evaluar el aprendizaje del tema el agua, el título podría ser Relatoría crítica sobre El agua. Del mismo modo sucedería con otros temas: las vocales, Cenicienta, intolerancia política, logaritmos, tabla periódica, relieve, textos argumentativos, etcétera).

Fuente. Si se solicita elaborar una relatoría a partir de un texto oral, escrito o visual, es necesario discriminar el título de este, nombre del autor y otros elementos básicos de este tipo de referencia. Si se trata de un tema de estudio (abordado en clase o para consulta), se relaciona: tema, asignatura, curso, profesor.

Relator. Nombre del sujeto o sujetos o equipo que elabora la relatoría, indicando datos relevantes. Si éste es estudiante, se relaciona, además de nombre y apellido, curso, asignatura, profesor, fecha, institución, ciudad; si se trata de un profesor: área y grados de desempeño pedagógico, fecha, institución, ciudad.

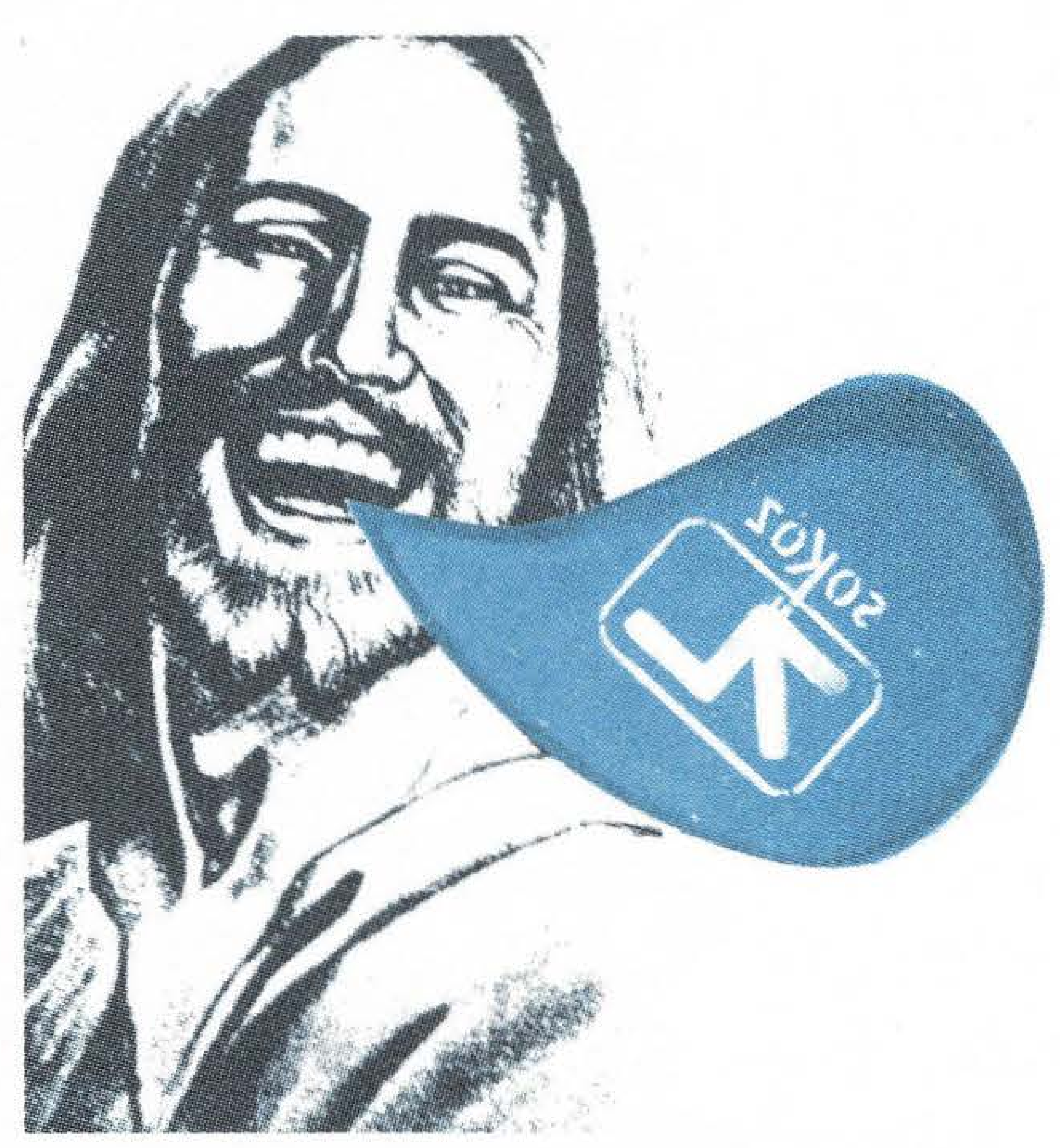

Introducción. Este aparte consta de tres tópicos, el primero de los cuales se podría obviar: generalidades, propósito, importancia. Se puede colocar como título interior, más no los componentes de esta. En generalidades el relator presenta una situación propia del tema -base de la relatoría o relacionada con este. Tal situación, caso, evento, fenómeno debe suscitar la atención del lector, bien porque es conocida para él o porque sobrepasa su dominio. En todo caso es una información que serviría de precedente para presentarle a este último los propósitos específicos, justificación e importancia de esa relatoría. En propósito se formula la finalidad o el reto que se propone el relator con esta ${ }^{8}$. Se sugiere incluir dentro del propósito el análisis de tópicos o ideas relevantes en el tema, situación, fenómeno o texto $\boldsymbol{x}$, presentando una posición personal frente a cada tópico o aspecto que se examine, y proponiendo ideas de mejoramiento. Por ejemplo, padre de familia y niño pueden, como relatores, fijar como propósito: "Criticar las acciones del lobo y de Caperucita, proponiendo ideas para no mentir ni hacer el mal en la familia, la escuela y la sociedad". Un estudiante de primaria puede, por ejemplo: "Explicar las ideas o aspectos más importantes del tema Las Figuras geométricas, proponiendo ideas, según el número de lados, para mejorar en algunos aspectos de la vida" (o proponiendo y resolviendo problemas). 


\section{Análisis crítico}

El análisis crítico de un tema u otro objeto de estudio precisa del relator abordar dos macroprocesos interrelacionados: el examen de ideas y su actitud ante las mismas o ante un tópico relacionado con estas 9 . Véase a continuación uno y otro.

Analizar es el proceso en virtud del cual se repara en aspectos específicos o relevantes de un objeto (tema de clase, texto, evento, situación), estableciendo relaciones entre estos y otros del mismo u otros objetos. Todo tema de clase u objeto de estudio involucra varios aspectos, tópicos o ideas ${ }^{10}$. De acuerdo con el propósito de relatoría el análisis debe abordar al menos uno de estos. Aún centrado en un solo aspecto el análisis debe relacionar este con otros del mismo objeto, y si se prefiere, con otros objetos o aspectos de estos. Por ejemplo, si se trata de un tema como "las plantas", el relator puede examinar el proceso de fotosíntesis, su incidencia en la vitalidad de una planta, o puede explicar enunciados o declaraciones correspondientes a varios tópicos (definición de planta y de otros subconceptos, partes, clases, funciones o utilidad de las plantas, entre otros); no basta que explique cada enunciado o proceso (caso en el cual es relevante que el relator conozca el método semántico para el análisis de constructos ${ }^{11}$ ), es menester que explicite las razones y aclaraciones que ofrezca en cada evento, presentando casos o situaciones paradigmáticas, que ilustren aquellos.

9 Para conducir de manera más eficaz el análisis y evaluación de ideas y razonamientos que debe realizar el pensador crítico, valdría la pena considerar las preguntas que Paul - Elder (2003) recomienda en estos eventos, las cuales incluyen los elementos básicos de este modo de pensamiento:

Propósito ¿Qué trato de lograr? ¿Cuál es mi meta central? ¿Cuál es mi propósito?

Información ¿Qué información estoy usando para llegar a esa conclusión? ¿Qué experiencias he tenido para apoyar esta afirmación? ¿Qué información necesito para resolver esa pregunta?

Inferencias/ Conclusiones ¿Cómo llegué a esta conclusión? ¿Habrá otra forma de interpretar esta información?

Conceptos ¿Cuál es la idea central? ¿Puedo explicar esta idea?

Supuestos ¿Qué estoy dando por sentado? ¿Qué suposiciones me llevan a esta conclusión?

Implicaciones/ Consecuencias Si alguien aceptara mi posición, ¿Cuáles serían las implicaciones? ¿Qué estoy insinuando?

Puntos de vista ¿Desde qué punto de vista estoy acercándome a este asunto? ¿Habrá otro punto de vista que deba considerar?

Preguntas ¿Qué pregunta estoy formulando? ¿Qué pregunta estoy respondiendo?

10 Un tema como las vocales (en preescolar) suscita, de acuerdo con los intereses de los estudiantes o del profesor, así como con los estándares o logros formulados por el docente, tópicos tales como: definición de vocal, las vocales, pronunciación, número de vocales, clases de vocales, las vocales y la música, las vocales y el amor, entre otros que constituyan objeto o medio de apropiación, uso y vivenciación de este marco de estudio. Al respecto es importante que el profesor elabore un Mapa de tópicos y lo enseñe a sus estudiantes para que, en conjunto, lo fortalezcan o reelaboren (Arboleda, 2000, 2008).

11 El método semántico representa un constructo mediante el cual se exponen los argumentos, razones, explicaciones y explicitaciones que sustentan un enunciado o declaración. Para que un sujeto construya el significado de una información es necesario que examine esta. Nadie construye conocimiento si no es capaz de representarse semánticamente aquella, explicar lo que dice o refiere. Ante un enunciado el método precisa: a) dar al menos dos argumentos (de porqué se dice lo que asevera), b) explicar cada argumento o razón, c) ofrecer (de ser posible) un ejemplo que ilustre el enunciado, sustentando este. Una ampliación de este método se encuentra en Arboleda 2007- 2008. 
En un sentido técnico la crítica es la actitud que manifiesta un sujeto frente a un evento, proceso o declaración, poniendo de presente un pensamiento propio, auto-dirigido, auto-disciplinado, autorregulado y auto-corregido. El carácter crítico de la relatoría estaría no precisamente en la explicación de los enunciados o procesos que se analizan, sino en la independencia de pensamiento del relator, en su posición frente a estos, en que manifiesta, sustenta y justifica su adherencia o desacuerdo con el conocimiento declarativo o con el proceso en cuestión. Si frente a la declaración contenida en un texto "La inequidad genera violencia" un sujeto expone y explica varios argumentos, estos deben tener como referente el contexto de enunciación, es decir las circunstancias en las que fue formulada la aseveración por el enunciador (profesor o autor del texto o discurso). En este caso no ha operado aún un pensamiento verdaderamente independiente.

La autonomía de pensamiento, es decir la actitud crítica se manifiesta, bien cuando este toma posición (personal) frente a la declaración, en la que puede argumentar a favor o en contra de toda o parte de la misma, bien cuando infiere, construye y argumenta él mismo el enunciado a partir de la información que le ofrece el discurso objeto de acercamiento, o, entre otros eventos, cuando teje nuevas razones a partir de su consulta en otros textos o contextos. Es posible que en la argumentación primaria o condicionada a las características que impone el enunciador el relator presente razones diferentes de aquellas que expresaría en su argumentación independiente o crítica. Por ejemplo, si frente al enunciado en referencia el relator argumenta, ceñido a los elementos que expone el enunciador, que la persona humana no merece ser excluida de los beneficios sociales, motivo por el cual algunos individuos manifiestan actos violentos, y además explica y explicita esta razón; su pensamiento crítico se pondría de manifiesto si expresara adecuada y fiablemente que está de acuerdo o en desacuerdo con la declaración, que la violencia opera al tiempo como causa y consecuencia de la inequidad, si no defiende la violencia como efecto de inequidad, en fin, si sintoniza en su posición razones y eventos que hagan parte de su experiencia de mundo.

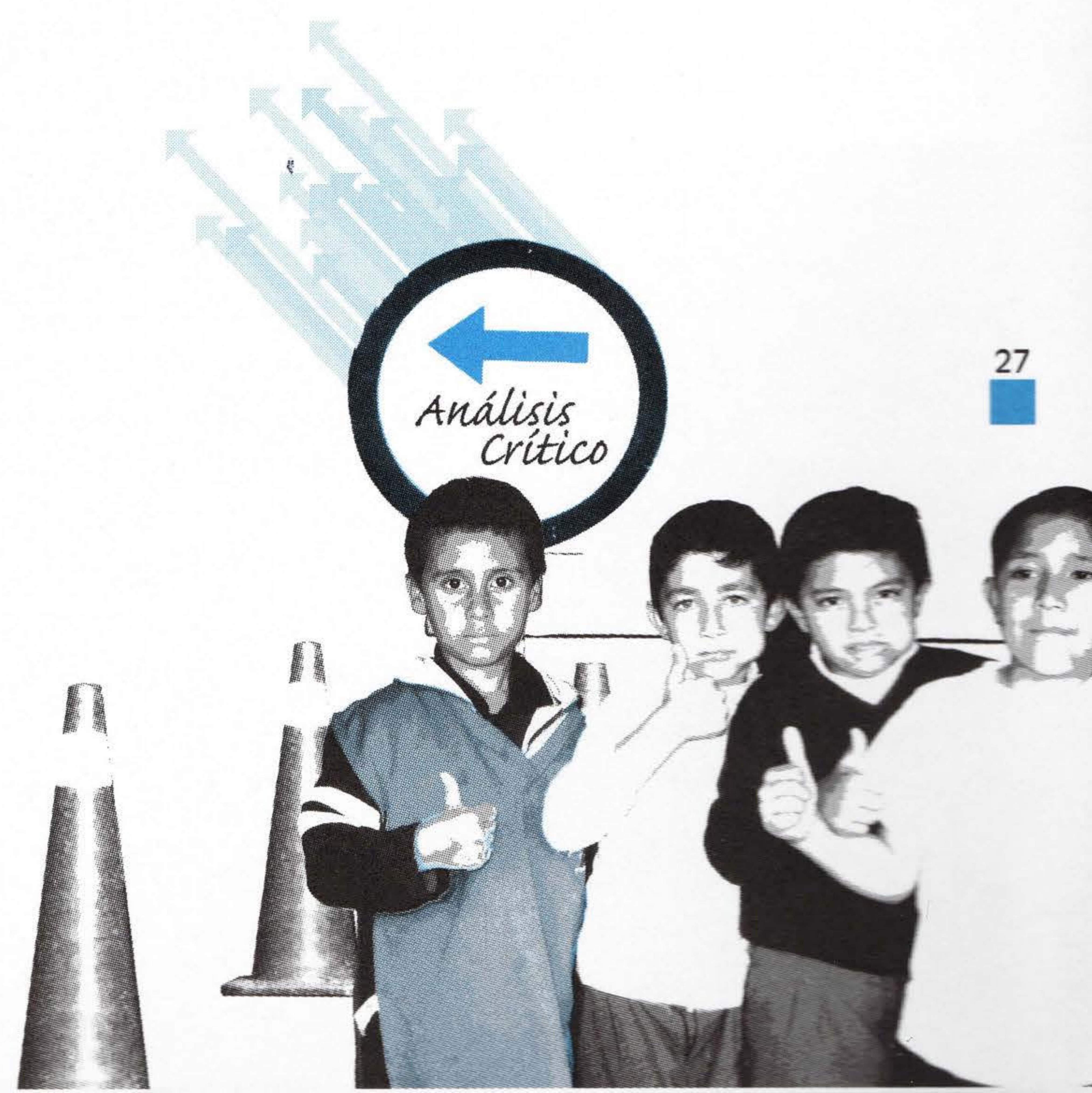




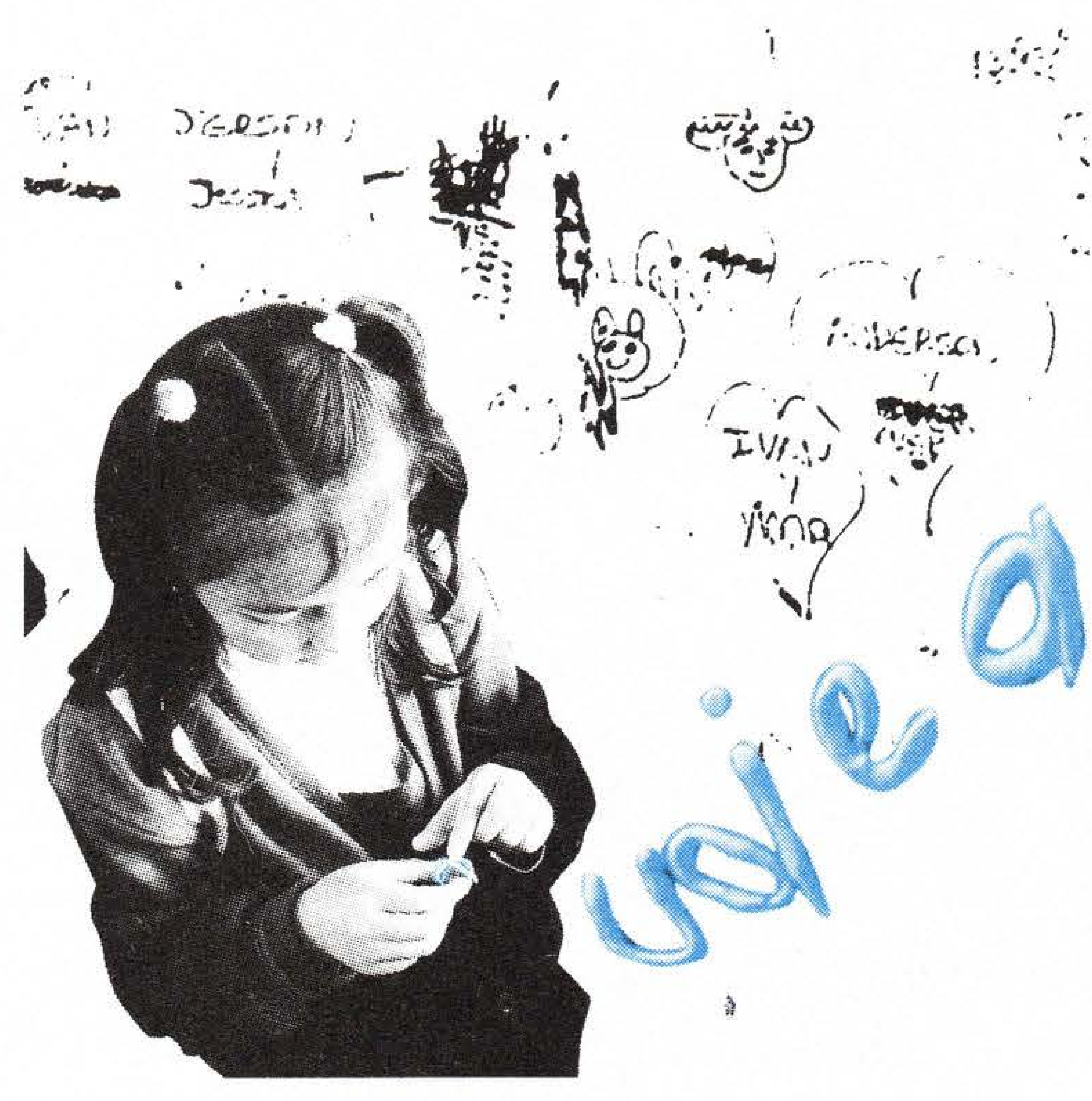

Síntesis proactiva

En un párrafo el relator sintetiza las ideas analizadas y formula propuestas de mejoramiento. La generación de ideas es un acto que hace de la crítica un proceso edificador, que va más allá del análisis y la evaluación, en busca de mejores caminos para avanzar en el aspecto, situación o evento en los cuales se repare. Ahora interesa explorar ideas para asumir la relatoría con este modo de pensamiento.

\section{Desarrollo del pensamiento crítico}

La exigencia que hace este tipo de texto al relator, referente a realizar interpretaciones fiables y tomar posición desarrollando una argumentación razonada, soportada en criterios de claridad, relevancia, profundidad, precisión, evidencia y equidad, convierte la formación de pensamiento crítico en un imperativo. Como se ha expresado hasta ahora, la relatoría demanda saber operar en el dominio de la comprensión y la producción discursiva, incluidos los procesos de lectura y escritura. El éxito en tales procesos dependerá de la capacidad, habilidad y actitud de aquel para fundamentar las razones que ofrezca frente a los enunciados declarativos o eventos que se expongan. Esto se debe a que, así como el aprendizaje de la lectura y la escritura es condición para la apropiación, uso y generación adecuados de conocimiento, el pensamiento crítico lo es para el fortalecimiento de todos estos procesos.

En esta dirección, el desarrollo de la relatoría precisa que el pensamiento crítico atraviese todos los procesos cognitivos y discursos, incluida la interpretación. Respecto a los primeros, esta última operación cognitiva es necesaria tanto para entender el objeto de estudio como para expresarlo en un lenguaje, sea escrito, oral, visual o fónico. Una interpretación es una apreciación en la cual también se manifiesta el punto de vista de quien la hace. Si el punto de vista está basado en creencias o dogmas, la interpretación será malsana, sesgada, inadecuada, igual que los argumentos que la justifiquen. Como se sabe, el pensamiento crítico va en contravía del sesgo, el dogma, la unilateralidad, la mente cerrada; precisa, por el contrario, de una mente abierta, flexible, desprejuiciada. Muchos textos carecen de pensamiento crítico cuando involucran inferencias, categorizaciones, análisis, síntesis o relaciones bajo el influjo de un pensamiento vertical deseoso de ver solamente lo que le provoca mirar, acomodando las situaciones, eventos o enunciados a su esquema ortodoxo. 
Respecto al proceso de la producción discursiva no basta dominar las técnicas formales de escritura. Un texto coherente también se caracteriza por ser portador de un pensamiento basado en argumentos razonables, independientemente del credo de su autor. En vía de ejemplo, le faltaría fuerza a un texto que desarrollare una idea científica con argumentos débiles y razones sesgadas. Sería un texto que en el plano formal talvez posea cierto grado de coherencia local y global, pero dejaría mucho que ver desde un punto de vista sustantivo relativo a las razones fiables.

La presencia de pensamiento crítico en uno y otro proceso obedece a la necesidad de emitir lo que M. Lipman denomina juicios inteligentes, es decir que la fiabilidad de los argumentos y aseveraciones que se formulen resida en los criterios de peso que los sostengan. Un argumento razonable, evidencia de pensamiento crítico, entraña interpretaciones adecuadas del evento, aseveración o situación que se examina, y no debe poder contradecir los hechos, depender absolutamente de estos, ni ser percibido, según se expresa arriba, como un pensamiento sesgado, dogmático, contestatario, basado en prejuicios y soportado más en la razón que en los sentimientos, o recíprocamente.
De acuerdo con lo expuesto, no basta que el relator sea capaz de interpretar o expresar adecuadamente el significado de la experiencia, situación, evento, dato, juicio, convención, creencia, regla, procedimiento, criterio, en fin, del objeto al que se acerca. Dado que el pensamiento crítico es una actitud, es necesario que la elaboración de la relatoría incluya, además de conocimientos, habilidades y destrezas discursivas, actitudes para construir textos con sentido a la luz de las características propias de esta facultad. La actitud debe acompañar la capacidad, por ejemplo, de presentar, examinar, discutir, sintetizar o expresar con claridad una información, argumentación, conclusión, punto de vista, exposición oral, escrita o visual, infiriendo sólo aquello que se desprenda de la evidencia, verificación e identificación de las implicaciones positivas y negativas de una consecuencia, entre otros potenciales relacionados en el informe del Proyecto Delphi ${ }^{12}$ capacidad de formular en forma apropiada categorías, distinciones o marcos de referencia; de caracterizar información, describir experiencias, situaciones, creencias, eventos; de reconocer un problema y definir su carácter; determinar una manera para seleccionar y clasificar información; clasificar datos, hallazgos u opiniones utilizando un determinado esquema de clasificación; diferenciar en un texto una idea principal de las ideas subordinadas; elaborar tentativamęnte una categorización o forma de organización de algo que se estudia.

Enseguida se precisa el carácter edificador de la relatoría crítica.

12 El proyecto Delphi es un estudio sobre pensamiento crítico realizado por un grupo interdisciplinario integrado por cuarenta y seis hombres y mujeres expertos de todas partes de los Estados Unidos y de Canadá. El proyecto de investigación duró dos años y se realizó en nombre de la Asociación Filosófica Americana. El trabajo resultante se publicó bajo el título de Pensamiento Crítico: Una Declaración de Consenso de Expertos con Fines de Evaluación e Instrucción Educativa. (The California Academia Press, Millbrae, California, 1990). Página Web: http://www.insightassessment.com/articles 


\section{Pensamiento crítico y formación integral}

El aprendizaje del pensamiento crítico es también una manera de aportar en el desarrollo de valores y otras actitudes, segmentos de la formación integral. Favorece, por ejemplo, la tolerancia y la autonomía. No se trata solamente de ejercer estos en las prácticas lectoescriturales, sino en todas las esferas de la vida que lo requieran. Más que una habilidad para proceder en el mundo académico se trata de una actitud para proceder en el mundo de la vida. En este sentido, la relatoría crítica cumple una funciọ́n edificadora, según se expone enseguida.

Respecto al valor de la tolerancia, no se puede ser verdaderamente crítico siendo injusto, excluyente, interesado en sí mismo, sectario o heterónomo. El crítico contamina su razonamiento cuando adecua las situaciones que examina a su ideología y soslaya puntos de vista diferentes. La tolerancia es una manera de ser crítico en la vida; de actuar inclusivamente con base en el reconocimiento y aceptación de sí mismo y del otro; pasa por reconocer que el mundo es asimétrico, que todos no son iguales ni tienen porqué serlos, que el otro es diferente en pensamiento, forma de ser, actuar, obrar, sentir y percibir. También se es crítico cuando se reconocen y aceptan los aciertos, errores, limitaciones, debilidades y potenciales propios.
Además de la tolerancia este aprendizaje favorece el desarrollo de la autonomía, de la independencia de pensamiento. En el mundo de hoy, bajo el influjo de proyectos utilitaristas, no se escatiman recursos para persuadir a las personas, agregándolas emocionalmente, y someterlas al arbitrio del consumo, del hedonismo, de la moda, al imperio de los medios de comunicación, de la eficiencia y la rentabilidad, imponiéndoles una dirección para sus vidas. Este hecho, en que el ser humano es permanentemente despersonalizado, demanda de la escuela la generación de oportunidades y capacidades para que el sujeto educable proceda en su existencia con pensamiento autónomo y actitud crítica, conozca e interprete la realidad, asuma creencias, pensamientos, actitudes y posiciones a la luz de su propia razón y de las evidencias, y ponga de presente la asimetría social, de pensamiento y credo en los procesos de su vida académica y cotidiana. De ahí la importancia de que la relatoría y, en consecuencia, el pensamiento crítico corran paralelas con los aprendizajes escolares.

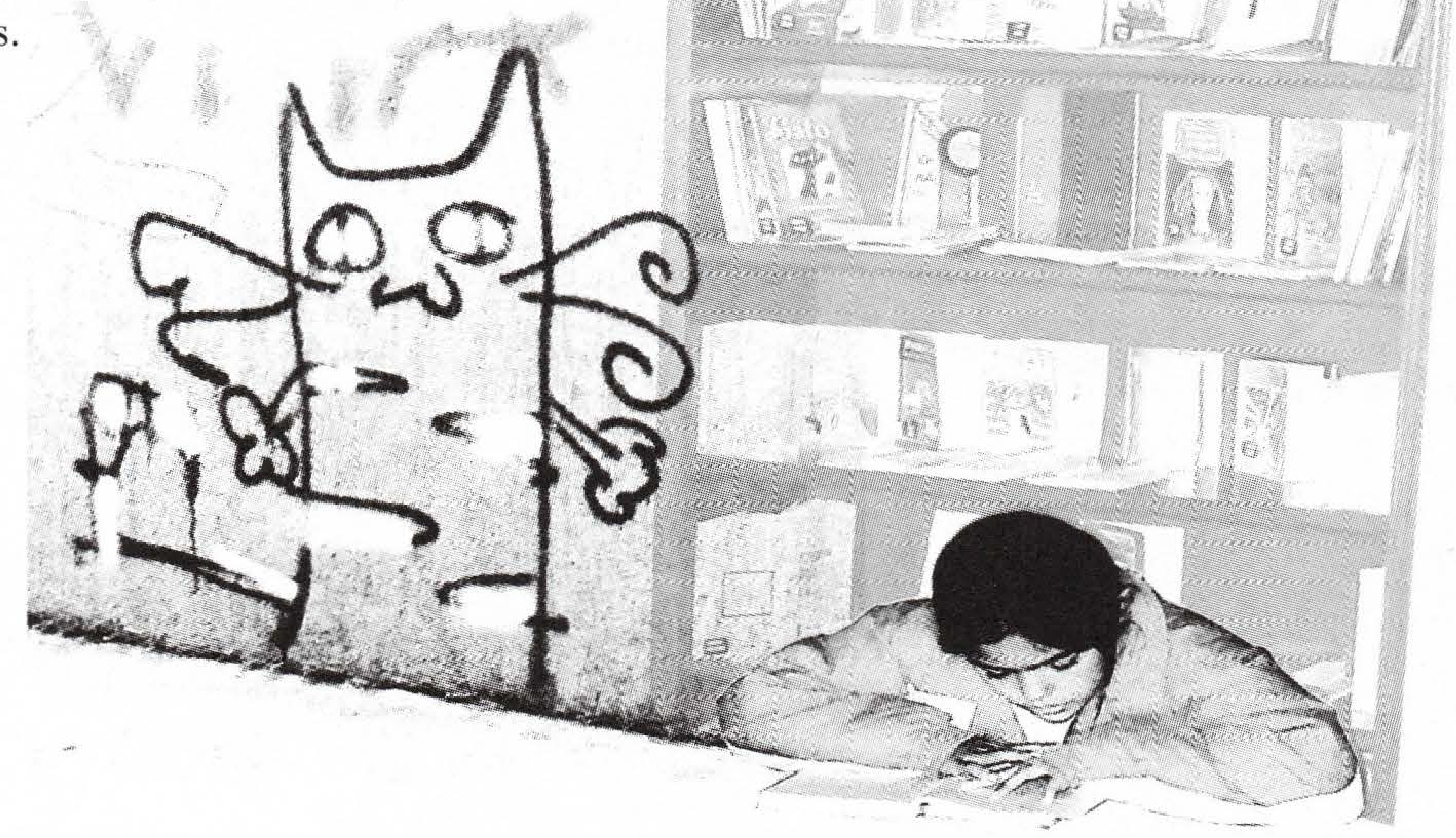




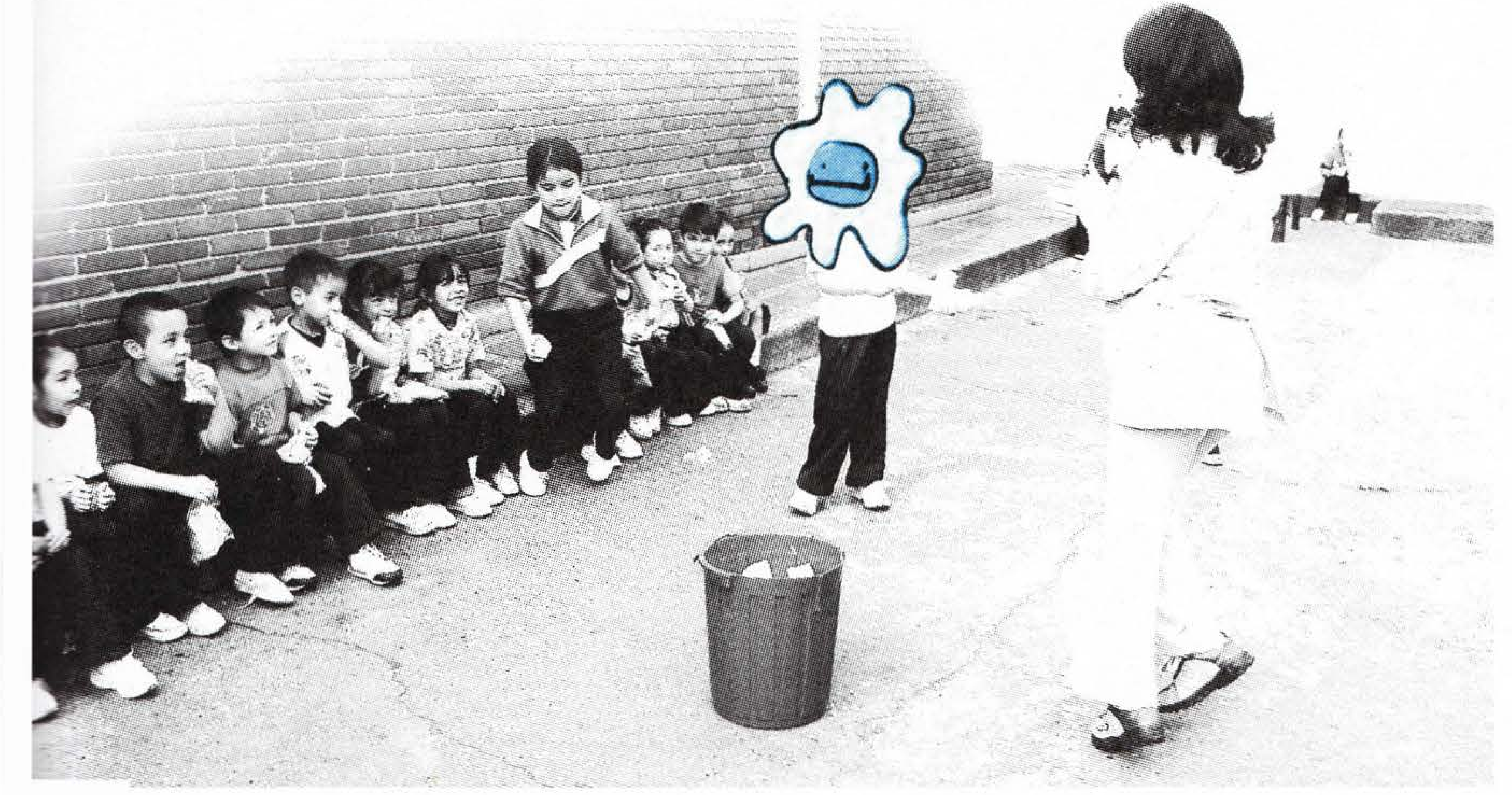

\section{Transversalidad de la lectura y la escritura}

La lectura y la escritura son procesos cuyo ejercicio promueve la formación de aprendizajes efectivos. La apropiación de conocimientos depende en gran medida de la capacidad cognitiva, afectiva, metacognitiva y operativa de un sujeto para interpretar la información que percibe, sea esta expresada a través de textos escritos y visuales, la pizarra del salón de clases, exposiciones orales, entre otros canales. Así mismo, depende de su capacidad para verbalizar, usar y resignificar esta en la elaboración de textos escritos. En consecuencia, leer interpretando información y resignificar esta como conocimiento escrito, son procesos necesarios en una acción pedagógica que promueva la formación de sujetos educables capaces de construir, aplicar y generar conocimiento ${ }^{13}$.

En este orden de ideas, la relatoría cumple una función sustantiva en el aprendizaje y la formación integral, pues, entre otras razones, para elaborarla adecuadamente se requiere de conocimientos, capacidades, habilidades y actitudes para apropiarse y comprender los textos, conceptos y discursos adscritos a los objetos de conocimiento y propósitos de la misma, y para operar con estos en la producción escrita. Tal función rinde mayores frutos si el currículum incluye un proyecto transversal que permita, por una parte, formar a los profesores y estudiantes en pensamientos múltiples, en particular, en el pensamiento crítico, y por otra, institucionalizarla, preferiblemente que sea elaborada en todas las áreas y niveles de escolaridad. En esta línea, es un falso problema pensar que se debe formar el pensamiento crítico como condición para elaborar relatorías. A mi modo de ver, las dos capacidades se deben formar y desarrollar al unísono con estrategias diferenciadas y comunes.

Igual sucede cuando se le asigna al profesor de lengua castellana la responsabilidad de la enseñanza de la relatoría, lo que constituye un desconocimiento de que cada área precisa modos de argumentación singulares; en consecuencia, es necesario que todos los profesores conozcan los mecanismos que permiten desarrollar el lenguaje específico de las disciplinas y campos de conocimiento desde los cuales interactúan con los estudiantes. Por esta razón, una primera capacitación de los docentes en la elaboración de relatorías críticas que incluya apartes sobre formación del pensamiento crítico, constituiría una oportunidad para iniciar un programa institucional que permita ejercitar a los estudiantes en esta herramienta.

\footnotetext{
13 El aprendizaje de la lectura y la escritura precisa otros conocimientos, tales como la estructura y tipología de los textos, la argumentación razonada, la elaboración de proposiciones, párrafos y, entre otros, usar adecuadamente operaciones y estrategias cognitivas, metacognitivas y discursivas (en la producción y la comprensión textual y conceptual)
} 


\section{A modo de síntesis: importancia de la relatoría en el aprendizaje}

La implementación de la relatoría crítica como estrategia para el aprendizaje se justifica, entre otras razones, porque da lugar a que los estudiantes desarrollen capacidades y ejerciten habilidades para construir tanto un lenguaje interior - para sí mismo, según L. Vygotski ${ }^{14}$ - que les permita apropiarse de los conocimientos, como aquellos- lenguaje para otros --para verbalizar o comunicar estos, sean de tipo oral, escrito, sonoro o visual. La relatoría no solo favorsece el desarrollo del lenguaje y la competencia escritural, sino que permite, por un lado, resignificar los conocimientos, potenciando su apropiación y uso, y por otro, asumir una actitud de tolerancia e independencia de pensamiento edificadoras de su vida personal y social.

Uno de los escenarios en los cuales se hace posible el uso de los conocimientos es el de la posición que debe tomar el relator frente a las declaraciones que se decanten en el acercamiento al objeto de estudio. Tal postura crítica, expresada a través de argumentos, sustentaciones, explicaciones y explicitaciones fiables, precisa de claridad conceptual o de cierto dominio del conocimiento. En este sentido, valdría la pena que las instituciones educativas incluyeran el aprendizaje y uso de la relatoría como una herramienta pedagógica en todas las áreas y niveles de escolaridad, generando espacios para que todos los docentes y estudiantes se apropien conceptual, afectiva, operativa y valóricamente de esta herramienta.
Formar el pensamiento crítico incluye generar oportunidades y capacidades para que los sujetos educables armonicen con la autocorrección, se sepan falibles, autocríticos, no se apeguen a pensamientos propios y de otros, no aparten de sus decisiones y juicios las creencias, opiniones, experiencias, intereses, preferencias, ni se sometan a estas.

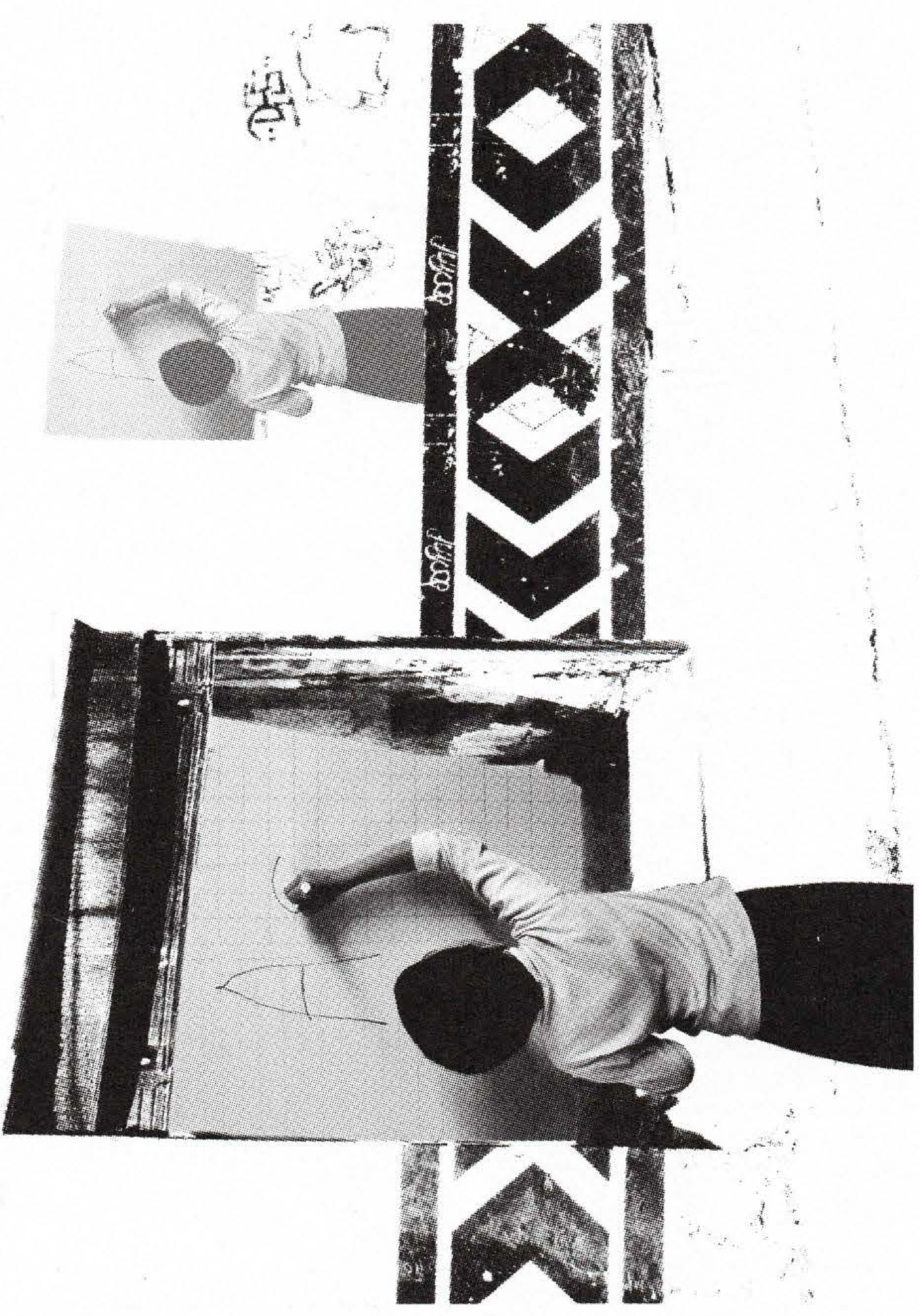




\section{Bibliografía}

Arboleda, Julio César. Ser persona en el mundo de hoy. Cali: Ed. Lei., 1995.

Instrumentos de lectoescritura. Cali: Ed

Lei, 1996.

Mapas cognitivos: lectoescritura, aprendizaje y desarrollo del pensamiento, Cali: Universidad Libre, 2000.

Relatorías y macrorrelatorías de investigación

en el aula. Cali: UAO, 2004.

Estrategias para la comprensión significativa.

Bogotá, D.C.: Editorial Magisterio, 2005.

Pensamiento lateral y aprendizajes. Bogotá,

D.C.: Editorial Magisterio, 2007.
Aprendizaje y comprensión: del enfoque de competencias al enfoque de comprensiones y proyectos de vida. Revista Educación y Cultura, №79 Bogotá, D.C.: CEID FECODE, $\mathrm{N}^{\circ} 79,2008 \mathrm{~A}$.

2008 .

Desarrollo de comprensiones, en prensa.

Lipman, Mathew. El pensamiento crítico: ¿Qué puede ser? Bogotá, D.C.: Educational Leadership, Vol.46 Nº1 Universidad Javeriana, Vol.46, №1, Traductor Diego Pineda, 1993.

Paul-Elder. Mini-guía para el Pensamiento crítico: Conceptos y herramientas. Fundación para el Pensamiento Crítico, 2003 www.criticalthinking.org

Vygotski, L. Penseé et langaje, París: Terrains Ed. SS, 1985. 


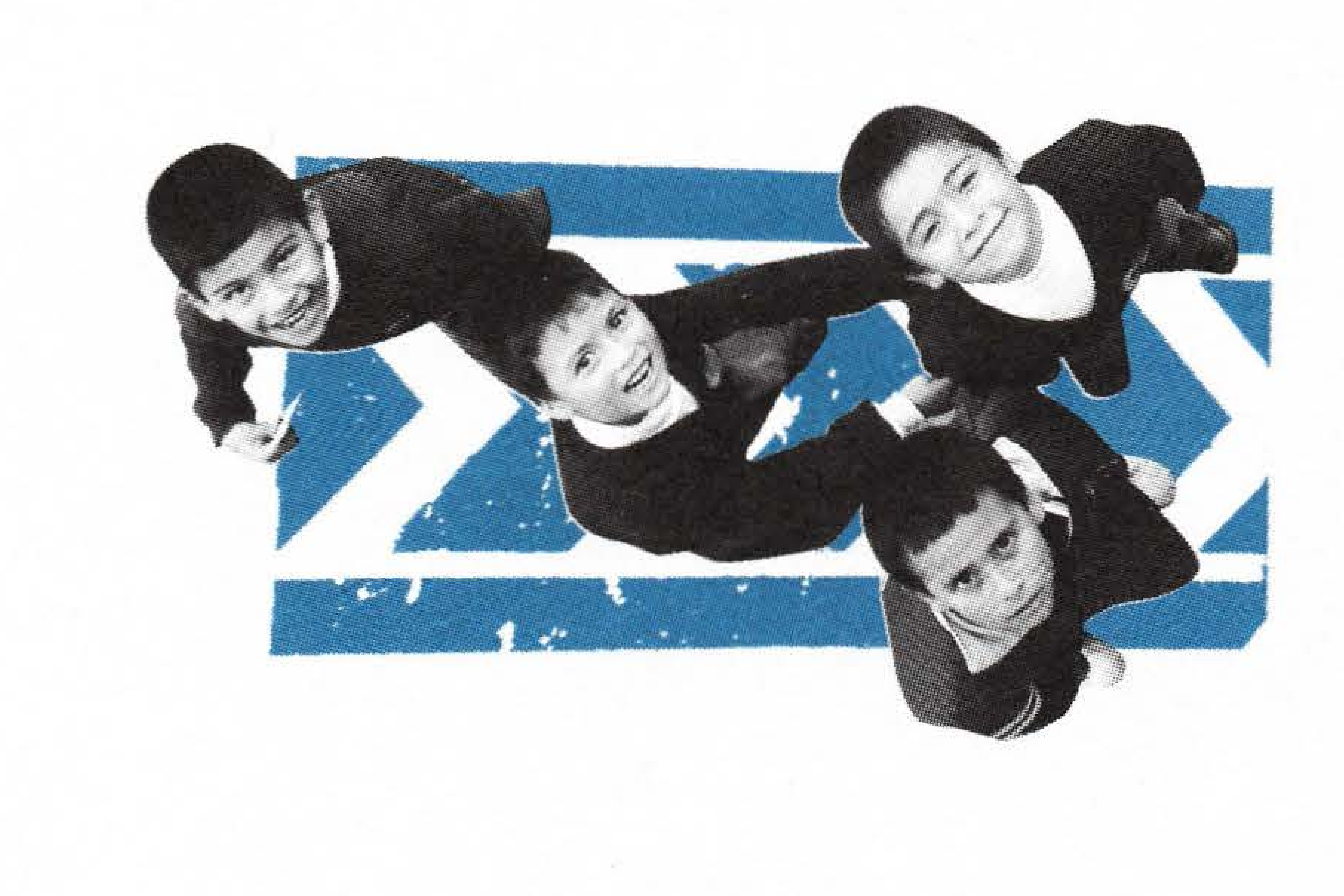

